\title{
Trendwatcher or trendsetter; 50 years of MTAA
}

\author{
Marcel de Bruin • Peter Bode
}

Received: 21 June 2011/Published online: 10 July 2011

(C) The Author(s) 2011. This article is published with open access at Springerlink.com

\begin{abstract}
The development on neutron activation analysis (NAA) into a technique of practical interest effectively started about 60 years ago, when nuclear reactors became available and widely accessible as intense sources of neutrons. During 50 out these 60 years, the series of Modern Trends in Activation Analysis (MTAA) Conferences acted as a true companion and facilitator of this growth. As trendwatcher they signalized the many initiatives that contributed to the development of activation analysis and its applications. A period has come to an end of impressive development resulting from sometimes revolutionary changes in radiation detection and data processing, and much improved irradiation facilities, NAA has reached a full stage of development, with emphasis on routine application and with remaining developments of in marginal impact. NAA is being challenged increasingly in the last 30 years by alternative techniques for multi trace element analysis. The MTAA Conference and with it the ICAA, the International Committee on Activation Analysis, can play an important and active role in this process of identifying and selecting key areas, and even promoting concerted action in those areas. Such an evolution of focus from retrospective to prospective, from trendwatcher to trendsetter, may well allow the MTAA Conference to continue and even expand its role in future development of NAA and its applications. The ideas about the future of the MTAA Conferences and its organization are elaborated upon and some possible subjects for focused development activities are indicated.
\end{abstract}

M. de Bruin · P. Bode $(\square)$

Faculty of Applied Sciences, Reactor Institute Delft, Department of Radiation, Radionuclides and Reactors, Delft University of Technology, Mekelweg 15, 2629 JB Delft, The Netherlands e-mail: p.bode@tudelft.nl
Keywords Neutron activation analysis - MTAA . Maturity $\cdot$ Trends $\cdot$ Decline $\cdot$ New challenges

\section{Introduction}

The history of neutron activation analysis (NAA) formally started in 1934, when George de Hevesy and Hilde Levi demonstrated the feasibility of nuclear activation for element analysis in one of their many famous experiments, [1]. For many reasons it remained a Sleeping Beauty until by the early 1960 s a stormy development started. Following the Atoms for Peace initiative, research reactors became widely available as intense neutron sources. This development was further boosted by the introduction of transistorized equipment, semiconductor detectors and laboratory computers in the next two decades.

The initiative for the first MTAA conference in 1961 coincided with the onset of the period of growth of NAA and so far, the MTAA conference series has paralleled 50 years of its history. During these 50 years, the MTAA Conferences have played a key role in the development of NAA as an international meeting point of those involved in development or application of the new analytical technique. It might be interesting to analyse how the developments of NAA over the past 50 years were reflected in the successive conferences. What can be learned from this past with respect to the future of NAA is even more important and this may reveal how the MTAA conference series can support and direct a sound development.

For a historical perspective, the contributions to the programs of the successive MTAA Conferences were analyzed [2-13]. These contributions were divided into specific categories and subjects according to the focal point of their 
Table 1 Categories and subjects therein identified amongst the contributions to 13 MTAA conferences between 1961 and 2011

\begin{tabular}{ll}
\hline Development & $\begin{array}{c}\text { Activation } \\
\text { Thermal neutrons } \\
\text { Basic data }\end{array}$ \\
Methodology & \\
Irradiation and flux parameters \\
(Chem) separation
\end{tabular}

content (Table 1). As such, trends could be observed along the successive MTAA conferences over the past 50 years.

The second categorization was by grouping these contributions on basis of type of activation: thermal (reactor) neutrons or others (epithermal and fast neutrons, charged particles, photons). It appears that that over the last five conferences, about $85 \%$ of the contributions referred to thermal neutron activation (Fig. 1). The scope of this evaluation will be therefore focused on the trends in thermal neutron activation analysis (NAA).

Various trends are clearly visible in the data on the twelve Conferences, although somewhat scattered by statistics, geographical effects and interpretations. The two most significant historical trends may be of substantial relevance for the future of NAA:

- Development versus Application versus Metrology

- Applications in Life- and Earth Science versus Applications in Material Science.

\section{Development, application, metrology}

The trends in the numbers of contributions in the categories Development, Application and Metrology, expressed in percentages of the total numbers of contributions, are shown in Fig. 2. It reveals a (significant) change of the ratio of contributions dealing with method development and those dealing with applications: from an average ratio of 1:1 over the five meetings before 1980 to almost 1:2 over the five meetings after 1990. This change of focus from development to application, particularly when observed in a series of conferences dealing specifically with "Modern Trends" is a strong indicator of the present status of maturity of NAA: indeed, the technique can be considered as 'fully developed'. It is seldom realized that there have not been significant breakthroughs in sensitivity and specificity of NAA since the introduction of the semiconductor detector and laboratory computers in the 1960s. One might even conclude that at present, 20-30 years after reaching this state of maturity, a decline
Fig. 1 Contributions on activation by thermal neutrons and other radiation as $\%$ of total contributions to MTAA conferences

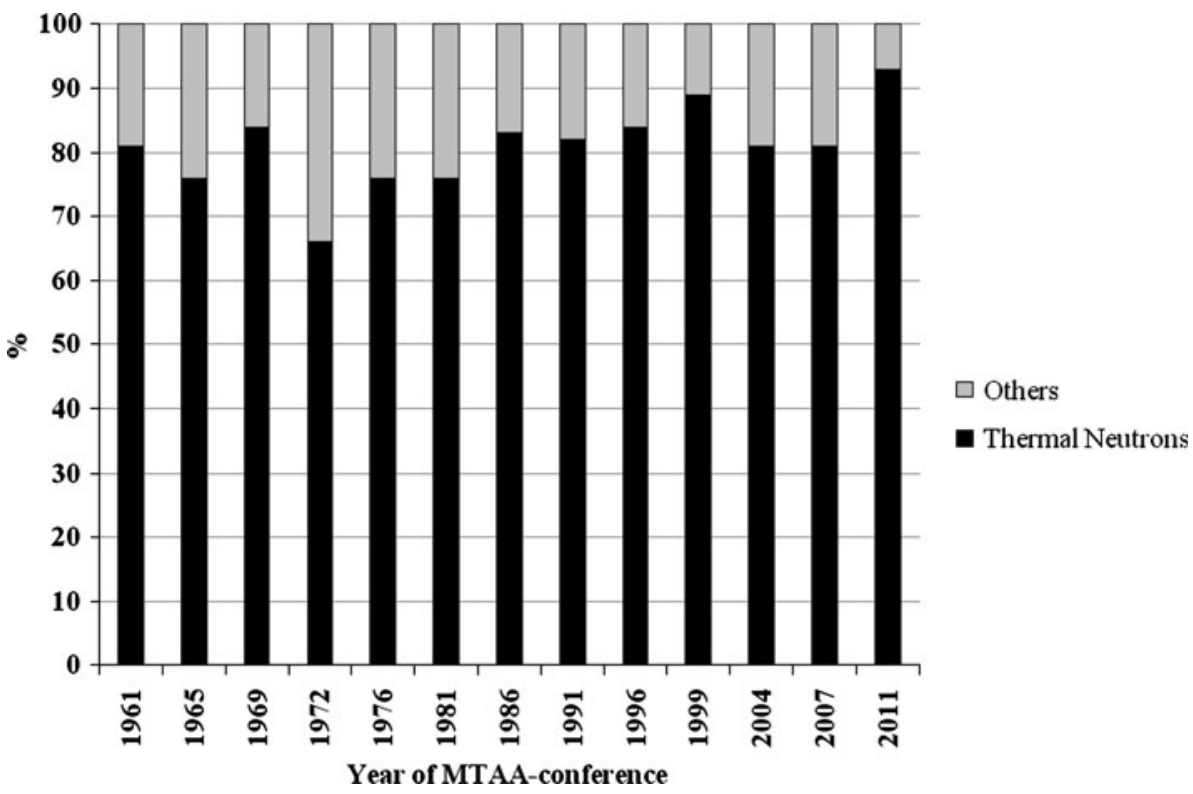


Fig. 2 Contributions on specific subjects as \% of total number of contributions to MTAA conferences

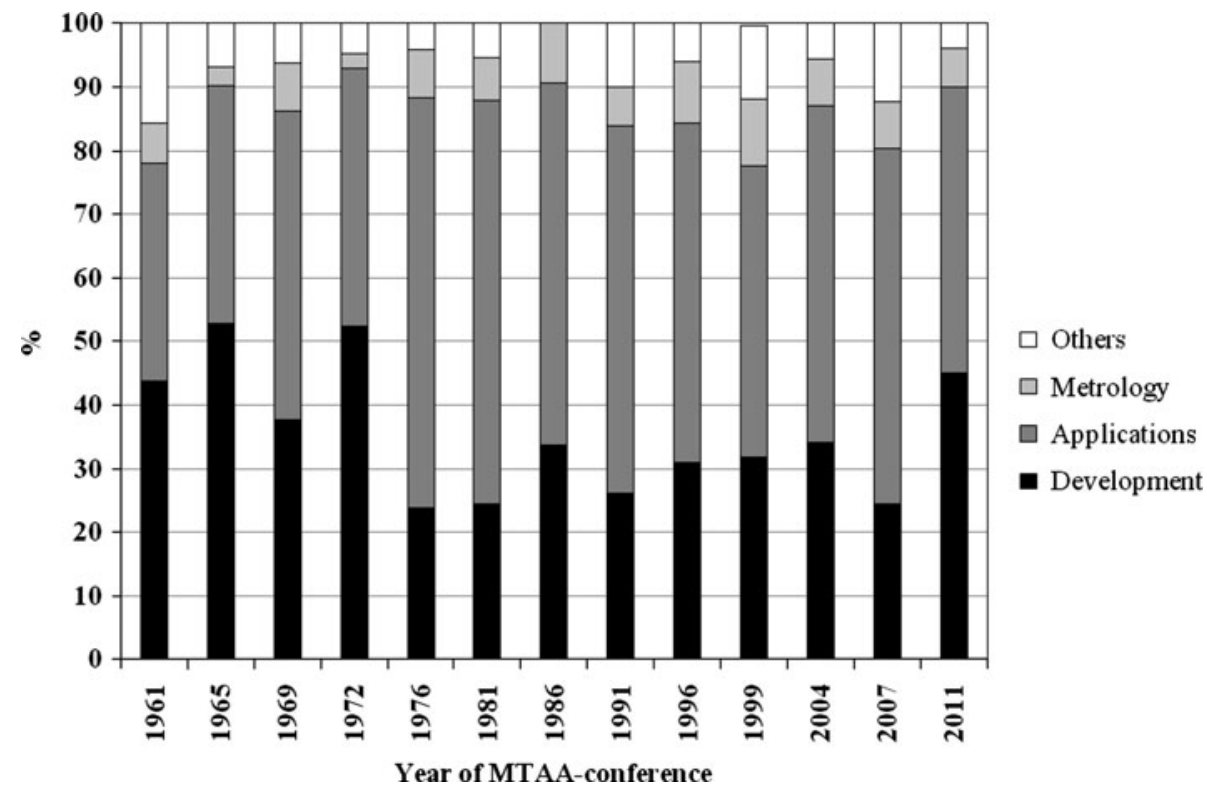

of the relevance of NAA may be imminent. Therefore, actions should be considered to ensure a sound further development of NAA as an analytical technique of practical relevance. Fortunately, the most recent MTAA conferences (2007-2011) have yielded a number of individual, interesting, sometimes even exotic ideas, ranging from the use of muons to the integration of substoechiometric approaches in chemical separations. Effective stimulation of new developments seems to be a matter of focus and concerted action rather than availability of ideas or capacity.

A second interesting development showing up in Fig. 2, is the significant increase of the attention paid to metrology, representing the aspects relevant for the quality of the analytical results. The contributions in this category mostly deal with standards, CRM's, evaluation of the uncertainty of measurement and assessment of neutron fluence rate parameters - the latter being basically a further refining of the single comparator method introduced in 1965 by Girardi [14]. Surprisingly, little attention is paid to the possibly largest source of errors in chemical analysis, namely the sampling error reflecting poor representativeness of the test portion to the population sampled. This may be quite relevant in routine NAA in which relatively small sample (few hundreds of $\mathrm{mg}$ ) are used. From the studies of e.g., Kratochvil [15] it appears that larger sample sizes can be necessary to minimize sampling errors particularly when analysing geological or environmental samples. Therefore, development of systems for routine analysis of samples of intermediate size, i.e., 1-10 g, might be beneficial for the accuracy and, implicitly, for the applicability and future relevance of NAA.

\section{Applications in Life- and earth sciences versus applications in materials}

Applications of NAA in Life- and earth Sciences (geology, biomedicine + food + environment) and Material Sciences constitute more than $90 \%$ of the application oriented contributions, as can be seen from Fig. 3. Particularly interesting in this figure is the growth over the years of the first two groups of applications from 40 to $50 \%$ to more than $90 \%$, whereas applications to material sciences are falling down from $40 \%$ to below practically insignificant.

It is not a surprise that the first category, biology and geology, constitutes such a large portion of the NAA application. The physical aspects of the NAA process fit very well to the materials from these fields. The broad spectrum of element concentration data fits in many cases very well to the exploring character of the investigations. Moreover, timescales of the investigations in this category are in general long compared to the relatively long turn around time of many NAA procedures.

It is also not surprising that NAA has become more or less irrelevant in material science. This is mainly due to the complete misfit between the characteristics of materials, particularly of metals, and the characteristics of NAA. Typical for analyses of materials are: (1) a well defined analytical question, (2) urgency because of relation with industrial processes, and (3) an often strongly activated matrix after neutron irradiation. Material science has an increasing interest in mass fraction distributions along surfaces. As an example, the silicon industry has moved to (in-house) techniques such as SIMS, Auger electron spectroscopy, Total reflection XRF, X-ray photoelectron 
Fig. 3 Contributions on different applications of NAA as $\%$ of total number of contributions on applications

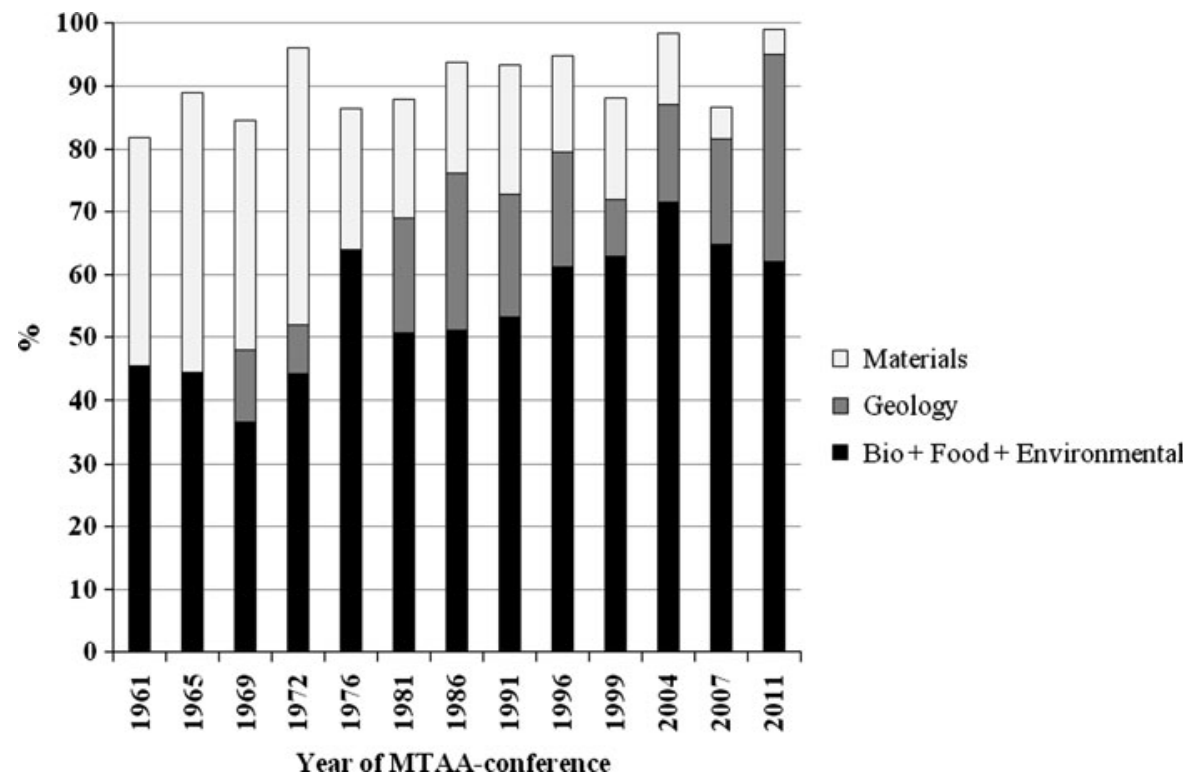

spectroscopy and RBS for their elemental analysis also because NAA cannot provide the sensitivity anymore for the amounts of impurities in ultrathin surface layers. On the other side the chain, recycling of various metal groups, including the lanthanides, asks for fast on-line analytical procedures of strongly inhomogeneous material streams.

Nonetheless, it seems worthwhile for the NAA community to try reclaiming part of the market share of materials analysis. This market represents a very large economic interest and investing in NAA methods for materials can be of substantial financial and strategic interest for NAA laboratories in addition to the obvious scientific challenge. Points for special consideration include a systematic approach of (chemical) separations of bulk activities, state-of-the-art high count rate spectrometry for better usability of short half-life radionuclides, and further development of existing physical techniques for studies of surface layers and interfaces into quantitative analytical applications.

\section{Conclusions: the future}

The programs of the successive MTAA Conferences clearly show a stormy development on the methodology of NAA in the period 1960-1980, followed by an already extended period of maturity, reflected by a vast range of applications. Being the devil's advocate, it may be questioned if many of these applications are still build on the analytical uniqueness of NAA or merely done because NAA was available anyhow. Of course, the same may be argued about how other techniques are being applied. A well directed effort in further development of the methodology for staying tuned with today's and the future needs for element determinations is of primary importance to exploit fully the potentials of NAA and to avoid an eventual decline of its practical relevance. It may require attention to the significant improvement in detection limits, turn-around time, and expansion to position-sensitive element determinations.

The activation analysis community is very well positioned, through its MTAA Conference series and the International Committee on Activation Analysis (ICAA), to stimulate focused and coordinated development activities aiming at further improving quality and practical applicability of (N)AA techniques. This was done in the past by the International Atomic Energy Agency (IAEA) through its Coordinated Research Program mechanism, but also the IAEA has put its priorities for such support in the last decade in areas other than NAA, which may reflect the previously indicated reduced relevance of the technique. The ICAA as a body of experienced and respected specialists can identify and prioritize directions for further development of activation analysis methodology, instrumentation and application, as starting point for discussion at new MTAA Conferences. The results of such a process may lead to corresponding and early announced topical sessions in such a new MTAA Conference. This may be an additional stimulus for a focused and concerted action.

Developing along these lines from a trendwatcher towards a trendsetter, the MTAA Conference series can contribute to a healthy further development of activation analysis. It may also contribute to bridge with other fields of science or with user communities of large research facilities.

Directions for further development are easily identified amongst the simple analysis of the programs of the MTAA conferences, as well as from developments in neighboring disciplines. Our personal favorites include: 
- Facilities for routine analysis at competitive conditions of intermediate size samples $( \pm 10 \mathrm{~g})$

- Facilities for analysis of large, strongly inhomogeneous samples from recycling processes

- Position-sensitive determination of elements

- Exploration and development of prompt NAA methods for analysis of surface and interface layers:

- Development of neutron depth profiling into a method for quantitative analysis on routine basis.

- Investigation of the possibility to incorporate neutron scattering techniques as n-reflectometry in NAA procedures for surface layers

- Implementation of LaBr-scintillators [16] with state-ofthe-art spectrum analysis software [17] in high countrate gamma-spectrometry systems for short half-life nuclides.

\section{Final note}

The considerations in the above were drafted preceding the 13th International Conference on Modern Trends in Activation Analysis (MTAA-13), held in College Station, TX, USA, March 13-18, 2011. The contributions at MTAA-13 [18] were also categorized and already processed in Figs. 1, 2 and 3. It can be observed that for the first time for long, a significant growth occurred in contributions related to method and facility development. Possibly more people may have identified with us the threatening decline in this over the past decades and actions have been taken. Several of these newest contributions demonstrate that out-of-thebox thinking, i.e., introducing and adapting innovations from other fields of science can yield successful improvements for NAA. The change in trends in the contributions during MTAA13 in comparison to the previous in the series emphasizes that also the design of the conferences is critical in this, e.g., by the invitation of people and by including topical workshops on areas such as nanotechnology. As such, MTAA13 may be classified as a trendsetter rather than a trendwatcher.

Open Access This article is distributed under the terms of the Creative Commons Attribution Noncommercial License which permits any noncommercial use, distribution, and reproduction in any medium, provided the original author(s) and source are credited.

\section{References}

1. Hevesy G, Levi H (1936) Det. Kgl. Danske Videnskabernes Selskab. Mathematisk-fysiske Meddelelser XIV 5:3-34

2. (1961) Proceedings of 1961 International Conference Modern Trends in Activation Analysis, College Station, TX, USA, Dec $15-161961$

3. (1965) Proceedings of 2nd International Conference Modern Trends in Activation Analysis, College Station, TX, USA, April 19-22, 1965

4. (1968) Proceedings of 3rd International Conference Modern Trends in Activation Analysis, Gaithersburg, MD, USA, Oct 7-11, 1968. In: De Voe JR, LaFleur PD (eds) NBS Special Publication 312, 2 vols

5. (1973) Proceedings of 4th International Conference Modern Trends in Activation Analysis, Saclay, France, Oct 2-6, 1972. J Radioanal Chem 15-16 and 17-19

6. (1977) Proceedings of 5th International Conference Modern Trends in Activation Analysis, München, Germany, Sept 13-17, 1976. J Radioanal Chem 37-39

7. (1982) Proceedings of 6th International Conference Modern Trends in Activation Analysis, Toronto, Canada, June 15-19, 1981. J Radioanal Chem 69-72

8. (1987) Proceedings of 7th International Conference Modern Trends in Activation Analysis, Copenhagen, Denmark, June 23-27, 1986. J Radioanal Nucl Chem 112-114

9. (1993) Proceedings of 8th International Conference Modern Trends in Activation Analysis, Vienna, Austria, Sept 16-20, 1991. J Radioanal Nucl Chem 167-169

10. (1997) Proceedings of 9th International Conference Modern Trends in Activation Analysis, Seoul, South Korea, Sept 24-30, 1995. J Radioanal Nucl Chem 215-216

11. (2000) Proceedings of 10th International Conference Modern Trends in Activation Analysis, Bethesda, MD, USA, April 19-23, 1999. J Radioanal Nucl Chem 244-245

12. (2007) Proceedings of 11th International Conference Modern Trends in Activation Analysis, Guildford, Surrey, UK, June 20-25, 2004. J Radioanal Nucl Chem 271

13. (2008) Proceedings of 12th International Conference Modern Trends in Activation Analysis, Hachioji, Japan, Sept 16-21, 2007. J Radioanal Nucl Chem 225-226

14. Girardi F, Guzzi G, Pauly J (1965) Anal Chem 37:1085-1092

15. Harris WE, Kratochvil B (1974) Anal Chem 46:313-315

16. Van Loef EVD, Dorenbos P, Van Eijk CWE, Krämer K, Gudel HU (2001) Appl Phys Lett 79:1573-1575

17. LaVigne E, Sjoden G, Baciak J, Detwiler R (2008) Proc SPIE 6954:695416-1-695416-11

18. (2011) Book of Abstracts 13th International Conference Modern Trends in Activation Analysis, College Station, TX, USA, March 13-18, 2011 